Document downloaded from:

http://hdl.handle.net/10251/30655

This paper must be cited as:

Rodriguez Martinez, ED.; Paya Bernabeu, JJ.; Monzó Balbuena, JM.; Borrachero Rosado, MV.; Bernal, SA.; Provis, JL. (2012). Structure of Postland cemente Pastes blended with sonicated silica fume. JOURNAL OF MATERIALS IN CIVIL ENGINEERING. 24:12951304. doi:10.1061/(ASCE)MT.1943-5533.0000502.

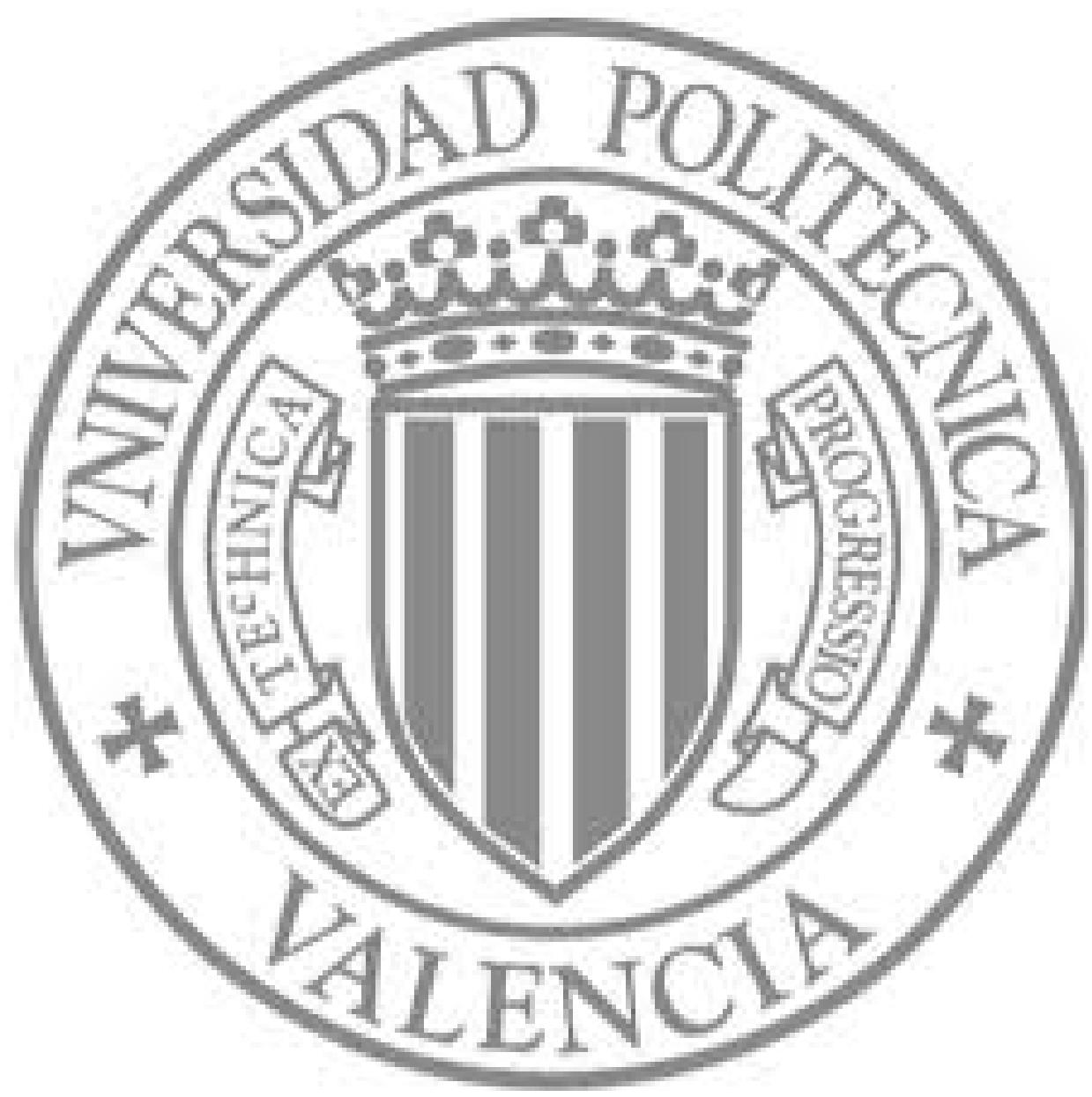

The final publication is available at

http://ascelibrary.org/doi/pdf/10.1061/\%28ASCE\%29MT.1943-5533.0000502

Copyright American Society of Civil Engineers 


\title{
Structure of Portland cement pastes blended with sonicated silica fume
}

Erich D. Rodríguez 1*, Susan A. Bernal 2, John L. Provis 3, Jordi Payá 4, José M. Monzó 5, and María Victoria Borrachero $6 *$

1 Instituto de Ciencia y Tecnología del Hormigón, Universitat Politècnica de València, 46022 Valencia, Spain. errodnar@disca.upv.es

2 Department of Chemical and Biomolecular Engineering, University of Melbourne, Victoria 3010, Australia.sbernal@unimelb.edu.au

3 Department of Chemical and Biomolecular Engineering, University of Melbourne,

Victoria 3010, Australia.jprovis@unimelb.edu.au

4 Instituto de Ciencia y Tecnología del Hormigón, Universitat Politècnica de València, 46022 Valencia, Spain.jjpaya@cst.upv.es

5 Instituto de Ciencia y Tecnología del Hormigón, Universitat Politècnica de València, 46022 Valencia, Spain.jmmonzo@cst.upv.es

6 Instituto de Ciencia y Tecnología del Hormigón, Universitat Politècnica de València, 46022 Valencia, Spain.vborrachero@cst.upv.es

\begin{abstract}
The application of power ultrasound to enhance dispersion of commercial densified silica fume (DSF) leads to increased compressive strengths and refinement of the pore structure in mortars, compared with samples prepared with untreated DSF. This is attributed to the enhanced pozzolanic reactivity achieved by particle dispersion through sonication, leading to higher consumption of portlandite during curing, and the formation of C-S-H gel with a higher degree of cross-linking than is identified in specimens with DSF. This suggests that with the use of sonicated SF, it is possible to reduce the amount of this admixture required in blended cements to achieve specified performance, with the additional advantage of the formation of a highly densified structure and refined pore network, contributing to potential improvements in durability.
\end{abstract}

Keywords: Silica fume, sonication, Portland cement, calcium silicate hydrate, pozzolan

\section{Introduction}

Silica fume (SF) is a by-product derived from the production of elemental silicon or alloys containing silicon, and consists of a non-crystalline silica dust formed during the oxidation of $\mathrm{SiO}$ vapor, which is mainly collected in baghouse filters of electric arc furnaces. The first report of the use of SF as a supplementary cementitious material (SCM) in building applications was 1942 (Sharp 1944), and since the 1970s an increased interest in its application and commercialization as pozzolanic material has been identified, due to the enhanced properties of the concretes which can be achieved through the use of Portland cement/SF blends. Currently, the chemical and physical properties of SF as a mineral admixture for concrete production using blended cements are standardized worldwide (ASTM C 1240 and EN-13263-1). The global SF production is estimated about 9.0×105 metric tons per year, of which 1.29×105 metric tons are used in concrete (EPA and U.S Department of Energy 2008). The Silica Fume Association (SFA) in the United States has reported than in 2004, 0.2\% of SF production was used as a raw material in blended cement production, $18.2 \%$ in clinker and $54.5 \%$ in concrete manufacture ( EPA and U.S Department of Energy 2008). The incorporation of SF as an admixture in Portland cement-based products leads to an enhancement of mechanical strength (Chung 2002), along with improved durability properties such as resistance to acid attack (Roy, et al. 2001), carbonation (Papadakis 2000), sulfate attack 
(Al-Amoudi 2002), chloride penetration (Shi 2004), and freeze-thaw cycling degradation (Hooton 1993). One of the most important characteristics of SF in this application is its small particle size, which is much smaller than the anhydrous cement particles, with sizes around 0.1- $0.5 \mu \mathrm{m}$ and specific surface area around $20,000 \mathrm{~m} 2 / \mathrm{kg}$ (Bye 1999). This contributes to the high reactivity of the SF. However, the very small particles can also act as a filler, improving the packing density in the concrete, and consequently reducing the permeability and enhancing the durability of these materials (Bentz and Stutzman 1994; Goldman and Bentur 1993). The chemical reaction between the SF and the portlandite $(\mathrm{Ca}(\mathrm{OH}) 2)$ promotes the formation of a calcium silicate hydrate (C-S-H) gel. Studies applying 29Si magic angle spinning nuclear magnetic resonance (29Si MAS NMR) to blended cements including SF have identified that the $\mathrm{C}-\mathrm{S}-\mathrm{H}$ formed in these systems has a higher chain length than the C-S-H formed by OPC hydration alone (Groves and Roger 1989; Richardson 2000; Sun et al. 1999). This is considered desirable from a durability point of view, because it is forming a more stable binding phase. However, as the availability of portlandite is finite, SF incorporation into the system is generally not beneficial beyond a substitution rate of around 12\% (Song et al. 2010), and the standards in place in some parts of the world limit its content to lower levels than this. For the commercial utilization of SF, densification is applied through an electrostatic process, in order to increase its density and facilitate storage and transport (Holland 2005). Individual nanosized and microsized particles of silica are condensed to form conglomerates of irregular or spheroidal shape with sizes as large as $100 \mu \mathrm{m}$. This densified silica fume (DSF) is one of the most commonly used SCMs, but its incorporation in concrete mixes usually induces reduction in slump, leading to increased consumption of expensive organic admixtures to achieve the required workability (Sakai et al 2009). Incompletely-reacted agglomerated particles of DSF have also been identified in hydrated pastes (Diamond et al. 2004; Yajun and Cahyadi 2003), suggesting that the full reactive potential of the material is not completely used, and thus a very expensive filler is being included into the binder.

In recent years, the application of high frequency ultrasound treatments to disperse DSF has been explored. Sonication enhances the effectiveness of SF as an SCM, associated with higher degree of consumption of portlandite over time of curing and higher mechanical strengths (Martínez et al. 2008; 2011). Sonicated aqueous suspensions of silica fume (SSF) show improved dispersion of sub-micrometer particles (Martínez et al. 2008; 2011; Rodríguez et al. 2011), where the volume of particles $<1$ ?] $\mathrm{m}$ increases by up to $60 \%$ compared with DSF suspensions (Rodríguez et al. 2011). This shows that ultrasonic treatment of DSF could be an attractive alternative to improve the efficiency of this admixture, as similar mechanical performance can be achieved using a lower amount of pozzolan, and a reduced content of unreacted particles would be present, enhancing durability. Ultrasonic treatment has been also carried out for other mineral admixtures in order to improve dispersion and reactivity (Frias et al. 2011). However, detailed structural characterization of pastes based on blends of OPC and SSF has not been reported in the open literature, and this is the aim of the present research. The effect of addition of a silica source with a high content of sub-micrometric particles (such as SSF) in the hydration products, performance and pore structures of blended cements is studied, and the results are compared with OPC binders including DSF, and reference binders solely based on OPC.

\section{Experimental program Materials}

An ordinary Portland cement type CEM-I 52.5, as classified by the EN 197-1 standard and supplied by Cemex, was used for the production of the samples. As the primary admixture, a commercial densified silica fume from ELKEM Silicon materials (Microsilica grade 940D) was used. The chemical compositions and physical properties of both raw materials are listed in table 1, and particle size information for the as-received DSF is given in figure 1.

As a fine aggregate for the preparation of mortars silica sand was used, with a specific weight of $2680 \mathrm{~kg} / \mathrm{m} 3$, absorption capacity of $0.17 \%$, fineness modulus of 4.1 , and particle size 
distribution adjusted following the standard DIN-EN-196-1.

Sample preparation and tests conducted

Ultrasonic treatment of DSF

Ultrasonic treatment of an aqueous suspension of DSF with a solid/liquid ratio of 0.20 was

carried out in using an S300 sonicator (MISONIX) for $15 \mathrm{~min}$, to obtain enhanced dispersion of SF particles. A maximum power of $600 \mathrm{~W}$ was applied, with an output frequency of $20 \mathrm{kHz}$. An external cooling bath was used during the treatment to avoid a rise in the temperature higher than $40^{\circ} \mathrm{C}$, which could lead to water evaporation. These experimental conditions have been chosen according to the findings of previous studies (Martínez et al. 2008; 2011; Rodríguez et al. 2011). The sonication shifted the particle size distribution towards lower particle sizes (Figure 1C), so that sonicated silica fume (SSF) presented an average particle size of $3.85 \mu \mathrm{m}$, a volume content of sub-micrometric particles of $56.9 \%$, and a d50 of $0.72 \mu \mathrm{m}$. Transmission electron microscopy (TEM) (figure 1A) shows the dispersion of these particles after the sonication treatment.

\section{Characterization of mortars}

The mechanical strengths of blended cements including densified silica fume (DSF), and the aqueous dispersion of silica fume obtained after the sonication treatment (SSF), were determined for mortars with substitution of $5 \%, 10 \%$ and $20 \%$ of cement by the SF admixtures. All mortars were produced with a water/binder $(\mathrm{w} / \mathrm{b})$ ratio of 0.30 , and sand/binder ratio of 2.0.

To achieve a workability between 190-220mm (determined according to UNE-EN 1015-3), a superplasticizer Glenium ACE31 from BASF with a relative density of $1052 \mathrm{~kg} / \mathrm{m} 3$ was used. There was no evidence of segregation in any of the mortars produced.

The dry DSF and anhydrous cement were separately mixed before the addition of the water and aggregate in the mixture, while the colloidal dispersion of SSF was directly mixed with the anhydrous cement to provide the mix water for these samples. The superplasticizer was also mixed with the water (or the colloidal dispersion of SSF) before sample preparation. The mixing procedure followed the standard EN-190-6. Cubic samples of $40 \mathrm{~mm}$ dimensions were cast and cured under saturated lime water at $25^{\circ} \mathrm{C}$ for up to 60 days. The mixes are described in table 2.

Compressive strength was determined after 7, 28 and 60 days of curing according to the standard method UNE-EN 1015-11. The pore size distributions of mortar specimens after 28 days of curing were determined through mercury intrusion porosimetry (MIP) using an AutoPore IV 9500 (Micromeritics Instrument Corporation) with an intrusion pressure between $13782 \mathrm{~Pa}$ and 227.4 MPa. Data were analyzed using the Washburn equation, with a contact angle of $130^{\circ}$ (Washburn 1921).

\section{Characterization of pastes}

Blended cement pastes with a w/b ratio of 0.5 were prepared with $10 \mathrm{wt} . \%$ substitution of DSF or SSF for OPC, along with a reference paste solely based on ordinary Portland cement. The specimens were produced by mechanical mixing for two minutes, then were cast in cylindrical plastic molds and cured at $25^{\circ} \mathrm{C}$ and a relative humidity of $90 \%$. After 28 days of curing the samples were milled, treated with acetone to prevent further hydration, and filtered and stored in sealed plastic containers until testing. The determination of the reaction products formed using the different admixtures was conducted by:

X-ray diffraction (XRD) using a Bruker D8 Advance instrument with $\mathrm{Cu} \mathrm{K} \alpha$ radiation and a nickel filter, with a step size of 0.020 and 4 s/step.

Thermogravimetric analysis (TGA/DTG) using a Perkin-Elmer Diamond instrument with a heating rate of $10 \circ \mathrm{C} / \mathrm{min}$ up to $1000^{\circ} \mathrm{C}$ in a nitrogen atmosphere; an alumina crucible of 100 $\mu \mathrm{L}$ was used and filled with $30 \pm 2 \mathrm{mg}$ of sample. Based on TGA/DTG results, the percentage of portlandite present, and thus also of portlandite fixed by the pozzolanic reaction, were calculated according to the method of Payá et al. (2003). 
Solid-state 29Si and 27Al magic angle spinning nuclear magnetic resonance (MAS NMR) spectra were obtained on a Varian Direct Drive VNMRS-600 spectrometer (14.1T) using a MAS NMR probe for $4 \mathrm{~mm}$ o.d. zirconia rotors and a spinning speed of $v R=10.0 \mathrm{kHz}$. 29Si MAS NMR experiments were acquired using a pulse width of $2.5 \mu \mathrm{s}$ and a relaxation delay of $30 \mathrm{~s}$, and 5500 scans. For 27AI MAS NMR experiments, a pulse width of $0.5 \mu \mathrm{s}$ was used to ensure reliability of the intensities observed for the 27Al central transition for sites experiencing different quadrupole couplings. 29Si and 27Al chemical shifts are referenced to external samples of tetramethylsilane (TMS) and a $1.0 \mathrm{M}$ aqueous solution of $\mathrm{Al}(\mathrm{NO}) 3.9 \mathrm{H} 2 \mathrm{O}$, respectively.

Scanning electron microscopy (SEM) was conducted using an FEI Quanta microscope (ESEM) with a $15 \mathrm{kV}$ accelerating voltage and a working distance of $10 \mathrm{~mm}$. The samples were evaluated in low vacuum mode. Attached to this instrument, a Link-Isis (Oxford Instruments) X-ray spectrometer system (energy dispersive spectroscopy (EDS)) was used to determine chemical compositions. The EDX experiments were performed on polished samples to assure a flattened surface.

\section{Results and discussion}

Compressive strength

An increase in compressive strength with time of curing is identified in all the samples assessed (figure 2). Mortars with SSF develop higher compressive strengths (by as much as $26 \%$ ) compared to the mortars with DSF, regardless of the percentage used. The mechanical strength of mortars including $5 \mathrm{wt}$.\% DSF is comparable to that obtained in reference samples without any mineral admixture at 7 and 28 days, as is the 7-day strength of the $10 \mathrm{wt} . \%$ DSF sample.

Conversely, 5 wt.\% SSF blended mortars present compressive strengths after 28 days of curing which are higher than those reported for 5DSF-M after 60 days of curing, proving the increased reactivity of the SSF even at relatively low contents in the binder. This effect is more evident with the inclusion of $10 \%$ of the admixture. After 28 days, 10DSF-M mortars exhibit higher mechanical strength than the reference mix or specimens with $5 \mathrm{wt} . \%$ of this admixture; however, the compressive strength remains lower than in 5SSF-M. The inclusion of $10 \mathrm{wt} . \%$ SSF (10SSF-M) leads to increments in the compressive strength of up to $36 \%$ compared to the reference sample, and $22 \%$ compared with 10DSF-M.

A lower compressive strength than the reference mortar is observed in 20DSF-M mortars at early age, when compared with the reference mortar (OPC-M). Similar compressive strengths at 7 and 28 days are obtained for 10DSF-M and 20DSF-M, confirming that the inclusion of more than $10 \mathrm{wt} \%$ of DSF does not contribute further to the mechanical performance of the mortars. However, increased contents of DSF do lead to substantial decrements in the workability of the mixes, along with an increased water (and/or superplasticizer) demand (Song et al. 2010). Conversely, higher percentages of SSF lead to higher mechanical strength, so that OPC/SSF mortars present compressive strength up to $40 \mathrm{MPa}$ higher than the reference samples after 60 days of curing.

\section{Mercury intrusion porosimetry}

Mercury intrusion porosimetry is a technique which is known to present some limitations in obtaining an accurate measurement of the pore size distribution of hydrated cements (Diamond 2000). However, it is widely used in the characterization of ceramics and cementitious materials, providing valuable information about threshold diameters and intrudable pore space, and is applied here to obtain semiquantitative information regarding pore structure and connectivity for hydrated blends of $10 \mathrm{wt} . \%$ SSF or DSF with OPC. The pore size distributions of the mortars (figure 3 ) show that the inclusion of either DSF or SSF induces a significant decrease in the content of pores in large size ranges $(0.1-100 \mu \mathrm{m})$, as well as a refinement of the pore network $(<0.01 \mu \mathrm{m})$. This effect is more significant with the inclusion of SSF, where a reduction by more than $20 \%$ in the volume of pores with diameters 
larger than $10 \mu \mathrm{m}$ is observed when compared with reference mortars (OPC). These large pores are associated with macroscopic flaws, including the interfacial transition zone (ITZ) between aggregates and hydrated paste (Leemann et al. 2006). The addition of mineral admixtures with high pozzolanic reactivity leads to a more discontinuous and less permeable pore structure, especially in the ITZ, where reaction between the silica-rich admixture and the portlandite is promoting the formation of highly densified products, increasing the tortuosity of the pore structure (Song et al. 2010). According to the literature (Ivorra et al. 2010; Poon et al. 2001), increasing SF content in an OPC blend from $5 \%$ to $10 \%$ can reduce the total permeable porosity by up to $25 \%$. Here, it is identified that this effect is more remarkable when using SSF due to its higher pozzolanic reactivity. Reductions in the total porosity from $8.6 \%$ in reference samples (OPC-M), to $6.3 \%$ with the inclusion of $10 \mathrm{wt} . \% \mathrm{DSF}$, and $5.0 \%$ with $10 \mathrm{wt} . \% \mathrm{SSF}$, are obtained.

\section{$\mathrm{X}$-ray diffraction (XRD)}

All samples assessed (figure 4) show as the main crystalline hydrate products: portlandite $(\mathrm{Ca}(\mathrm{OH}) 2$; Powder Diffraction File (PDF) card \# 00-004-0733), ettringite

(Ca6Al2(SO4)3(OH)12-26H2O, AFt; PDF \# 00-41-1451), calcium aluminate hydrate (Ca3Al2O6·xH2O, C-A-H; PDF \# 00-002-0083), and calcium monosulfoaluminate hydrate (Ca4Al2O6(SO4)·14H2O, AFm; PDF \# 00-042-0062). Low intensity peaks attributed to a C-S-H type gel (Ca1.5SiO3.5·xH2O; PDF \# 00-033-0306) were also observed. As a secondary reaction product tetracalcium monocarboaluminate (monocarbonate AFm, Ca4Al2O6CO3.11H2O, PDF \# 00-041-0221) is also identified, and phases associated with unreacted cement, particularly belite ( $\beta$-Ca2SiO4, C2S; PDF \# 00-033-0302) and alite (Ca3SiO5, C3S; PDF \# 00-042-0551) were also present. This suggests that complete cement hydration was not reached the times of curing assessed. Calcite was also detected (CaCO3; PDF \# 00-005-0586), which could be associated with the carbonation of the samples.

The incorporation of both DSF and SSF leads to a reduction in the intensity of the main peaks of portlandite $\left(34.09^{\circ} 2 \theta\right)$, and this is most remarkable for the samples with SSF after 60 days of curing, consistent with the increased extent of pozzolanic reaction. The reflections associated with C-S-H (29-30 2]) for SSF-blended cement exhibited a higher intensity, especially in samples with 60 days of curing, as the C-S-H phase appears to show a different structure (possibly related to a lower $\mathrm{C} / \mathrm{S}$ ratio) and slightly higher crystallinity in the presence of the pozzolanic additive. No significant effect of the inclusion of SSF on the formation of AFt and AFm phases was identified by XRD.

\section{Thermogravimetry/differential thermogravimetry (TG/DTG)}

Differential thermogravimetric (DTG) results for OPC, and pastes with $10 \mathrm{wt} . \%$ DSF and SSF, show (figure 5) three mass loss peaks in all samples, in the regions between $35-300$ ㅇ $\mathrm{C}$ with maximum intensity slightly above $100^{\circ} \mathrm{C}$, at $450-600 \circ \mathrm{C}$, and a small feature at $800-1000 \circ \mathrm{C}$. The OPC and DSF samples also show an additional distinct peak below $200^{\circ} \mathrm{C}$. The mass loss below $300^{\circ} \mathrm{C}$ corresponds to the water released from the hydrated phases, such as: hydrated

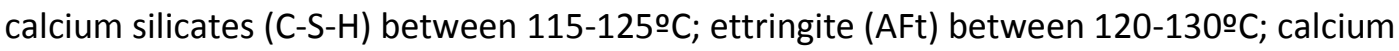
aluminates and silicoaluminate hydrates (C-A-H and C-A-S-H) between 160-180드. as well as monosulfoaluminates (AFm) between 185-200ㄷ (Taylor 1997). The second weight region is attributed to the dehydroxylation of water from the portlandite $(\mathrm{CH})$ between $440-550$ 으, while the third peak between $800-9000^{\circ} \mathrm{C}$ is assigned to decarbonation of calcium carbonate (Ramachandran et al. 2002). For the OPC paste, C-S-H and AFt are identified at $\sim 110 \circ \mathrm{C}$, and the peak at $\sim 160^{\circ} \mathrm{C}$ is assigned to calcium aluminate hydrates (C-A-H and C-A-S-H) of different compositions. Pastes with SF presented a higher loss weight at $\sim 110 \circ \mathrm{C}$, as a consequence of the additional $\mathrm{SiO} 2$ promoting higher formation of $\mathrm{C}-\mathrm{S}-\mathrm{H}$ through the pozzolanic reaction. In these samples, the peaks attributed to C-A-H, C-A-S-H and AFm are reduced in intensity and overlap, particularly for the case of the more reactive SSF. The dehydroxylation of portlandite is strongly visible at $\sim 450^{\circ} \mathrm{C}$ in OPC paste. This peak decreases with the inclusion of silica fume, and the quantities of portlandite consumed by the 
pozzolanic reaction with DSF and SSF can be quantified. Table 3 shows the total weight loss from $35^{\circ} \mathrm{C}$ to $1000^{\circ} \mathrm{C}$, the content of $\mathrm{CH}$ of the pastes studied, and the percentage of this portlandite which is consumed by the pozzolanic reaction. As is shown in table 3 , notable differences in the reactivity degrees of the two silica fume materials were identified. Pastes including SSF show $68 \%$ consumption of portlandite after 28 days of curing, while DSF gave only $28 \%$ consumption; these values increased slightly at 60 days.

The differences in reactivity identified between the SF admixtures can be attributed to the specific surface area and the dispersion of the particles. Materials with higher specific surface area and better dispersion are able to react with $\mathrm{CH}$ more effectively throughout the binder, rather than being localized in particular regions, meaning that the $\mathrm{Ca} 2+$ and $\mathrm{OH}$-contributed by $\mathrm{CH}$ require longer diffusion paths before reaching and reacting with the $\mathrm{SiO} 2$ particles. Thus, the pozzolanic reaction with $\mathrm{CH}$ occurs more quickly. Although $\mathrm{SF}$ is known to increase mechanical performance and improve durability properties in cementitious materials, it is possible to find some controversies regarding its effectiveness when used in its densified state (Lagerblad and Utkin 1995; Bonen and Diamond 1992; Sanchez de Rojas et al. 1999; Diamond et al. 2004; Sakai et al. 2009; Olek and Rangaraju 2000; Li et al. 1985; Mitchell et al. 1998). Mitchell et al. (1998) reported limited dispersion of SF agglomerates into the cement paste, and $\mathrm{CH}$ consumption as a consequence of pozzolanic reaction was observed only after 120 days of curing. Li et al. (1985) found that only $78 \%$ of their DSF was consumed by the cement paste after 90 days of curing, when $10 \%$ of this admixture was incorporated. These results are in good agreement with the lower reactivity identified in DSF when compared with SSF in the present study.

\section{Nuclear magnetic resonance spectroscopy (MAS-NMR)}

Figure 6 shows the solid-state 29Si-MAS NMR spectra of the cement pastes blended with $10 \%$ DSF or SSF after 28 days of curing. The spectra for every paste show the remaining $\beta-C 2 S$ from the clinker as a narrow resonance at $-72 \mathrm{ppm}$ relative to TMS (Q0 sites), which is consistent with the presence of belite in the XRD results. The main hydration product, $\mathrm{C}-\mathrm{S}-\mathrm{H}$, is identified through the resonances at $-80 \mathrm{ppm}$ and $-86 \mathrm{ppm}$, assigned to the species Q1 and Q2 respectively (Barnes et al. 1985). The aluminum present in the system can modify the C-S-H structure by substitution of tetrahedral Al into the bridging sites to obtain Q2(1Al) sites (Richardson et al. 1993). This substitution is observed by the presence of a shoulder at -83 ppm, which is mainly notable in the SSF paste. Unreacted silica fume (Q4), with a signal centered at -110 ppm, was also identified (Li et al. 1985; Zanni et al. 1996). The DSF-blended cement presented a high content of unreacted silica fume, as seen by the higher intensity of the signal centered at $-110 \mathrm{ppm}$. A broad signal at $-95 \mathrm{ppm}$ is also observed in pastes including DSF, which can be attributed to Q3 species, due to surface hydroxylation of the $\mathrm{SiO} 2$ particles remaining in the DSF binder. Silica gels contain Q3 species on the surfaces of $\mathrm{SiO} 2$ particles where bound hydrogen is present as silanol group (( $\mathrm{SiO}) 3 \mathrm{SiOH})$. This is also observed during the hydration of cement with silica fume whose surface has reacted with hydroxyl ions, forming Q3 units on SF particles (Sun et al. 1999). As the sample with SSF shows a low content of unreacted silica fume, the peak associated with the hydroxylation of unreacted $\mathrm{SiO} 2$ particles was not detected. The intensities of the hydrate product peaks, and in particular the Q2 and Q2(1Al) sites, are higher in the SSF sample, indicating the formation of additional C-S-H gel in this system.

The component peak areas and centre of gravity of the Qn species in the 29Si MAS NMR spectra were determined by deconvolution into Gaussian sub-peaks. The simulated spectra obtained after deconvolution are shown as dotted lines in figure 6 . Based on these results, and considering that the Q0, Q3 and Q4 peaks represent unreacted raw materials, the chemical structure of the $\mathrm{C}-\mathrm{S}-\mathrm{H}$ gel product can be estimated. The key parameters of interest are the average silicate chain length ( ), and the gel tetrahedral ratio, which are calculated through equations 1 and 2, respectively (Andersen et al. 2004; Richardson and Groves 1997), and are reported in table 4. 


$$
\begin{gathered}
\overline{C L}=\left(\frac{2\left(Q^{1}+Q^{2}(0 A l)+\frac{3}{2} Q^{2}(1 A l)\right)}{Q^{1}}\right) \\
A l / S i=\left(\frac{\frac{1}{2} Q^{2}(1 A l)}{Q^{1}+Q^{2}(0 A l)+Q^{2}(1 A l)}\right)
\end{gathered}
$$

The significant reduction (by around 50\%) of the intensity of the unreacted clinker (Q0) resonance is attributed to the inclusion of a finer SCM, such as SSF, accelerating the hydration process of C2S, and increasing the quantities of Q1, Q2(OAl), and Q2(1Al) species in the C-S-H phase, in agreement with the XRD results. The more homogeneously dispersed submicroparticles may also act more effectively as a nucleation agent for the formation of C-S$\mathrm{H}$ products (Li et al. 2004). Therefore, the kinetics of the pozzolanic reaction in pastes with SSF will be considerably higher than that exhibited by DSF-blended cement. This effect also contributes to the growth of C-S-H chains with higher values, a lower $\mathrm{Ca} / \mathrm{Si}$ ratio, and lower capillary porosity. The increase in with the inclusion of a finer SCM in a Portland cement system agrees well with the results from NMR spectra reported by Porteneuve et al (2002), who reported a higher average length of $\mathrm{C}-\mathrm{S}-\mathrm{H}$ when a finer silica fume was incorporated. Zanni et al. (1996) obtained values between 3 and 4 in hydrated cement pastes with $10 \%$ densified silica fume, w/b of 0.15 and 28 days of curing. Wang et al. (2011) also reported a of 3.7 in a cement Portland paste with $10 \%$ densified silica fume, $w / b$ of 0.30 and 120 days of curing, while Poulsen et al. (2009) reported between 4.85 and 5.21 in pastes with $10 \% \mathrm{SF}$, $\mathrm{w} / \mathrm{b}$ between $0.40-0.45$, and I to 28 days of curing. These differences could be attributed to the use of different experimental conditions, such as $w / b$, curing conditions, and types of cement (chemical composition and fineness) between the various studies.

The higher average chain length ( ), the increase in the concentration of Q2(1Al) units, and the higher AlIV/Si ratio obtained for SSF-blended paste also confirm the higher degree of Al substitution in the tetrahedral chains. For this reason, and also due to the changes in aluminate hydrate species as seen in the DTG data, it is proposed that 27AI MAS-NMR may give additional information, and these data are shown in figure 7. Anhydrous cement (CEM) spectrum exhibits a broad band centered at about $80 \mathrm{ppm}$, corresponding to overlapping resonances from AllV incorporated as a guest-ion in the alite and belite phases (Skibsted et al. 1994). AllV in tricalcium aluminate is also identified in the anhydrous sample by a broad signal around 40 to $80 \mathrm{ppm}$. The intensities of these resonances in hydrated samples (OPC, DSF and SSF) decrease significantly, and some of the intensity is converted to octahedrally coordinated Al, visible as three resonances assigned to ettringite ( $\sim 13 \mathrm{ppm})$, monosulfoaluminate ( $\sim 11$ ppm) (Skibsted et al. 1993) and the third aluminate hydrate phase ( $4 \mathrm{ppm})$. This third aluminate hydrate (TAH) phase has been classified either as a separate phase or as a nanostructured surface precipitate on the C-S-H phase (Andersen et al. 2006). The inclusion of the more dispersed SSF admixture significantly decreases the intensity of the AFm resonance and increases the intensity of the TAH resonance compared with the DSF-blended cement. $10 \%$ cement replacement by a mineral admixture with high reactivity, such as SSF, decreases the available aluminate content of the clinker, and also incorporates more Al into the C-S-H through the pozzolanic reaction as seen from 29Si MAS NMR, reducing the formation of AFm phases.

The broad resonance at $68 \mathrm{ppm}$ is typical of an AllV site in a less-crystalline structure (Andersen et al. 2003; Richardson, Brough, Brydson, Groves and Dobson 1993). This resonance is thus assigned to tetrahedrally coordinated Al incorporated in the C-S-H phase (Komarneni et al. 1985; Richardson et al. 1993). From the 27AI MAS NMR spectra, it is clear 
that the SSF-blended cement results in a larger quantity of Al becoming incorporated in the CS$\mathrm{H}$ structure, in agreement with the similar increase in the Q2(1Al) resonance observed in the 29Si MAS NMR spectra in Figure 6 and the higher Al/Si ratio in Table 4. There is also a very low-intensity resonance at $\sim 38 \mathrm{ppm}$ which is possibly attributed to the presence of AIV in the C-S-H phase (Faucon et al. 1999). Andersen et al. (2003) reported a direct relation between the aluminum substitution and the period of curing of Portland cement pastes. The higher degree of Al substitution in the gel here may thus indicate a higher effective maturity of the binder due to the pozzolanic reaction, and this is further enhanced by the SSF as a finer and more reactive mineral admixture.

\section{Scanning electron microscopy (SEM)}

Scanning electron micrographs of the hydrated samples blended with DSF and SSF are presented in figure 8 . Silica fume agglomeration was not identified in the paste with SSF (figure $8 \mathrm{~A}$ ), and this admixture thus presented better effectiveness in hydration as the dispersion enhanced the contact between the calcium-rich pore solution (in solubility equilibrium with portlandite) and the silica particles, meaning that more contact between $\mathrm{Ca2+}$ and $\mathrm{OH}$ - ions and active $\mathrm{SiO} 2$ species led to formation of additional C-S-H gel. SEM images of DSF blended cement paste reveal unreacted silica fume agglomerates larger than $100 \mu \mathrm{m}$ in size embedded in the hydrated paste, which were not disintegrated or dispersed during the mixing process (figure $8 \mathrm{~B}$ ). Figure $8 \mathrm{~B}$ reveals that these conglomerates of silica fume react only superficially with $\mathrm{Ca}(\mathrm{OH}) 2$, forming a reaction product layer covering the silica fume conglomerate. Accordingly, calcium and silicon EDX mapping images of hydrated paste with DSF show a very high content of $\mathrm{Si}$ in the inner region of the silica fume conglomerate, where $\mathrm{Ca}$ has not been able to access the $\mathrm{Si}$ to react. The microstructure of such agglomerates has been observed in several studies (Bar-Nes et al. 2008; Diamond et al. 2004; Yajun and Cahyadi 2003) and it is probable that such silica particles could act in effect as a small aggregate with a slight potential to react with alkalis in cement (Maas et al. 2007; Marusin et al. 2000). This possible mode of binder degradation is removed by the application of sonication to the silica fume, showing another possible benefit of this treatment.

\section{Conclusions}

The use of densified silica fume (DSF) as supplementary cementitious material in Portland cement based systems promotes an increased compressive strength, along with a reduced permeability, compared with materials solely based on Portland cement; however, it has been identified that DSF particles agglomerate and do not disperse homogeneously in the cement paste during conventional mixing. This leads to a reduction in the potential efficiency of the admixture.

The application of a high frequency ultrasound treatment to densified silica fume improves its pozzolanic reactivity through the dispersion of sub-micrometric silica particles. The use of sonicated silica fume as a mineral admixture for Portland cement systems promotes higher mechanical strengths and a refined pore network than is obtained when including densified silica fume at similar mass fractions. This highlights that when applying the sonication treatment assessed in this study, a desired mechanical strength can be achieved using a lower content of the admixture.

Sonicated silica fume presents a higher reactivity, associated with the increased consumption of portlandite during curing, when compared with pastes including densified silica fume, which leads to the formation of a C-S-H type product with a structure with a longer chain length, an increased silicon substitution by aluminum, and lower $\mathrm{Ca} / \mathrm{Si}$ ratio than systems including densified silica fume. These structural differences might lead to an improved durability of these materials in the long term, as a more stable binding phase is formed.

Acknowledgments

This study was sponsored by the Ministerio de Ciencia e Innovación of Spain (Project SILISONIC BIA-2007-63252 and research scholarship BES-2008-002440 and EEBB-201143847), the European regional development fund (FEDER), and the Universitat Politècnica de 
València (Spain). The participation of SAB and JLP was funded by the Australian Research Council (ARC), including partial funding through the Particulate Fluids Processing Centre, a Special Research Centre of the ARC. The authors would like to thank Dr. John Gehman for support in conducting the NMR experiments at the Bio21 Institute, University of Melbourne, Australia.

\section{References}

Al-Amoudi, O. S. B. (2002). "Durability of plain and blended cements in marine environments." Adv Cement Res, 14(3), 89-100.

Andersen, M. D., Jakobsen, H. J., and Skibsted, J. (2004). "Characterization of white Portland cement hydration and the $\mathrm{C}-\mathrm{S}-\mathrm{H}$ structure in the presence of sodium aluminate by $27 \mathrm{Al}$ and 29Si MAS NMR spectroscopy." Cement Concrete Res, 34(5), 857-868.

Andersen, M. D., Jakobsen, H. J., and Skibsted, J. (2003). "Incorporation of aluminum in the calcium silicate hydrate (C-S-H) of hydrated Portland cements: A high-field 27Al and 29Si MAS NMR investigation." Inorg Chem, 42(7), 2280-2287.

Andersen, M. D., Jakobsen, H. J., and Skibsted, J. (2006). "A new aluminium-hydrate species in hydrated Portland cements characterized by 27Al and 29Si MAS NMR spectroscopy." Cement Concrete Res, 36(1), 3-17.

Bar-Nes, G., Katz, A., Peled, Y., and Zeiri, Y. (2008). "The mechanism of cesium immobilization in densified silica-fume blended cement pastes." Cement Concrete Res, 38(5), 667-674.

Barnes, J. R., Clague, A. D. H., Clayden, N. J., Dobson, C. M., Hayes, C. J., Groves, G. W., and Rodger, S. A. (1985). "Hydration of Portland cement followed by 29Si solid-state NMR spectroscopy." J Mat Sci Lett, 4(10), 1293-1295.

Bentz, D. P., and Stutzman, P. E. (1994). "Evolution of porosity and calcium hydroxide in laboratory concretes containing silica fume." Cement Concrete Res, 24(6), 1044-1050. Bonen, D., and Diamond, S. (1992). "Occurrence of large silica fume-derived paticles in hydrated cement paste." Cement Concrete Res, 22(6), 1059-1066.

Bye, G. C. (1999). Portland Cement, Thomas Telford, London.

Chung, D. D. L. (2002). "Review: Improving cement-based materials by using silica fume." J Mat Sci, 37(4), 673-682.

Diamond, S., Sahu, S., and Thaulow, N. (2004). "Reaction products of densified silica fume agglomerates in concrete." Cement Concrete Res, 34(9), 1625-1632.

Diamond, S. (2000). "Mercury porosimetry: An inappropriate method for the measurement of pore size distributions in cement-based materials." Cement Concrete Res, 30(10), 1517-1525. EPA (United States Enviromental Protection Agency) in conjunction with the U.S. Department of Transportation and the U.S. Department of Energy (2008). "Study on increasing the usage of recovered mineral components in federally funded projects involving procurement of cement or concrete." Report to Congress (EPA 530-R-08-007)

Faucon, P., Delagrave, A., Richet, C., Marchand, J. M., and Zanni, H. (1999). "Aluminum incorporation in calcium silicate hydrates (C-S-H) depending on their $\mathrm{Ca} / \mathrm{Si}$ ratio." J Phys Chem B, 103(37), 7796-7802.

Frias M, Ramirez, M., Vigil de la Villa R, Gracias R, Rodriguez O, and Sanchez Rojas M. I. "Formation of hydrotalcite in activated paper sludge waste/Ca(OH)2 system." Proceedings of the 13th International Congress on the Chemistry of Cement, Madrid, Spain, July 2011, CDROM proceedings.

Goldman, A., and Bentur, A. (1993). "The influence of microfillers on enhancement of concrete strength." Cement Concrete Res, 23(4), 962-972.

Groves, G.W., and Rodger, S. A. (1989). "The hydration of C3S and ordinary Portland cement with relatively large additions of microsilica." Adv Cement Res, 2, 135-140.

Holland, T. C. (2005). Silica Fume User's Manual, U.S. Department of Transportation. Federal Highway Administration. Silica Fume Association (SFA), Washington. 
Hooton, R. D. (1993). "Influence of silica fume replacement of cement on physical properties and resistance to sulfate attack, freezing and thawing, and alkali-silica reactivity." ACl Mat Journal, 90(2), 143-151.

Ivorra, S., Garcés, P., Catalá, G., Andión, L. G., and Zornoza, E. (2010). "Effect of silica fume particle size on mechanical properties of short carbon fiber reinforced concrete." Mater Design, 31(3), 1553-1558.

Komarneni, S., Roy, R., Roy, D. M., Fyfe, C. A., Kennedy, G. J., Bothner-By, A. A., Dadok, J., and Chesnick, A. S. (1985). "27Al and 29Si magic angle spinning nuclear magnetic resonance spectroscopy of Al-substituted tobermorites." J Mat Sci, 20(11), 4209-4214.

Lagerblad, B., and Utkin, P. (1995). "Undispersed granulated silica fume in concrete: Chemical system and durability problems." Materials Research Society Symposia Proceedings, 370, 8998.

Leemann, A., Münch, B., Gasser, P., and Holzer, L. (2006). "Influence of compaction on the interfacial transition zone and the permeability of concrete." Cement Concrete Res, 36(8), 1425-1433.

Li, H., Xiao, H-G., Yuan, J., and Ou, J. (2004). "Microstructure of cement mortar with nanoparticles." Compos Part B-Eng, 35(2), 185-189.

Li, S., Roy, D. M., and Kumar, A. (1985). "Quantatative determination of pozzolanas in hydrated systems of cement or $\mathrm{Ca}(\mathrm{OH}) 2$ with fly ash or silica fume." Cement Concrete Res, 15(6), 1079-1086.

Maas, A. J., Ideker, J. H., and Juenger, M. C. G. (2007). "Alkali silica reactivity of agglomerated silica fume." Cement Concrete Res, 37(2), 166-174.

Martínez, D., Payá, J., Monzó J. M., and Borrachero M. V.(2011). "Effect of sonication on the reactivity of silica fume in portland cement mortars." Adv Cement Res, 23(1), 23-31.

Martínez, D., Payá, J., Monzó J. M., and Borrachero M. V. (2008). "Granulometric activation of densified silica fume (CSF) by sonication." Adv Cement Res 20(3), 129-135.

Marusin, S. L., and Bradford, S. L. (2000). "Alkali-silica reaction in concrete caused by densified silica fume lumps: A case study." Cement Concrete Aggr 22(2), 90.

Mitchell, D. R. G., Hinczak, I., and Day, R. A. (1998). "Interaction of silica fume with calcium hydroxide solutions and hydrated cement pastes." Cement Concrete Res, 28(11), 1571-1584. Olek, J. and Rangaraju, P. R. (2000). "Evaluation of the potential of densified silica fume to cause alkali-silica reaction in cementitious matrices using a modified ASTM C 1260 Test Procedure." Cement Concrete Aggr, 22(2), 150-159.

Payá, J., Monzó, J. M., Borrachero, M. V., and Velázquez, S. (2003). "Evaluation of the pozzolanic activity of fluid catalytic cracking catalyst residue (FC3R). Thermogravimetric analysis studies on FC3R-Portland cement pastes." Cement Concrete Res, 33(4), 603-609. Papadakis, V. G. (2000). "Effect of supplementary cementing materials on concrete resistance against carbonation and chloride ingress." Cement Concrete Res, 30(2), 291-299.

Poon, C. S., Azhar, S., Anson, M., and Wong, Y.-L. (2001). "Comparison of the strength and durability performance of normal and high-strength pozzolanic concretes at elevated temperatures." Cement Concrete Res, 31(9), 1291-1300.

Porteneuve, C., Korb, J-P., Petit, D., Zanni, H. (2002). "Structure-texture correlation in ultrahigh-performance concrete: A nuclear magnetic resonance study." Cement Concrete Res, 32(1), 97-101.

Poulsen, S., Jakobsen, H. J., and Skibsted, J. (2009) "Methodologies for measuring the degree of reaction in Portland Cement blends with supplementary cementitious materials by 27Al and 29Si MAS NMR spectroscopy." Proc., 7th IBAUSIL - Internationale Baustoffagung, 177-188. Ramachandran, V. S., Paroli, R. M., Beaudoin, J. J., and Delgado, A. H. (2002). Handbook of Thermal Analysis of Construction Materials, Noyes Publications, US.

Richardson, I. and Groves, G. (1997). "The structure of the calcium silicate hydrate phases present in hardened pastes of white Portland cement/blast-furnace slag blends." J Mat Sci, 32(18), 4793-4802. 
Richardson, I. G. (2000). "The nature of the hydration products in hardened cement pastes." Cement Concrete Comp, 22(2), 97-113.

Richardson, I. G., Brough, A. R., Brydson, R., Groves, G. W., and Dobson, C. M. (1993).

"Location of aluminum in substituted calcium silicate hydrate (C-S-H) gels as determined by 29Si and 27AI NMR and EELS." J Am Ceram Soc, 76(9), 2285-2288.

Rodríguez, E. D., Soriano, L., Payá, J., Borrachero, M. V., and Monzó, J. M. (2011). "Increase of the reactivity of densified silica fume by sonication treatment." Ultrasonics Sonochemistry (submitted).

Roy, D. M., Arjunan, P., and Silsbee, M. R. (2001). "Effect of silica fume, metakaolin, and low-calcium fly ash on chemical resistance of concrete." Cement Concrete Res, 31(12), 18091813.

Sakai, E., Kakinuma, Y., Yamamoto, K., and Daimon, M. (2009). "Relation between the shape of silica fume and the fluidity of cement paste at low water to powder ratio." J. Adv. Concr. Technol, 7(1), 13-20.

Sanchez de Rojas M.I., River J and Frias, M. (1999). "Influence of the microsilica state on pozzolanic reaction rate." Cement Concrete Res, 29(6), 945-949.

Sharp, J. W. (1944). "Silica Modified Cement." United States Patent 2,410,954

Shi, C. (2004). "Effect of mixing proportions of concrete on its electrical conductivity and the rapid chloride permeability test (ASTM C1202 or ASSHTO T277) results." Cement Concrete Res, 34(3), 537-545.

Skibsted, J., Henderson, E., and Jakobsen, H. J. (1993). "Characterization of calcium aluminate phases in cements by aluminum 27MAS NMR spectroscopy." Inorg Chem, 32(6), 1013-1027.

Skibsted, J., Jakobsen, H. J., and Hall, C. (1994). "Direct observation of aluminium guest ions in the silicate phases of cement minerals by 27AI MAS NMR spectroscopy." J Chem Soc Faraday T, 90(14), 2095-2098.

Song, H.-W., Pack, S.-W., Nam, S.-H., Jang, J.-C., and Saraswathy, V. (2010). "Estimation of the permeability of silica fume cement concrete." Constr Build Mater, 24(3), 315-321.

Sun, G., Brough, A. R., and Young, J. F. (1999). "Si NMR Study of the hydration of Ca3SiO5 and $\mathrm{B}-\mathrm{Ca} 2 \mathrm{SiO} 4$ in the presence of silica fume." J Am Ceram Soc, 82(11), 3225-3230.

Taylor, H. F. W. (1997). Cement Chemistry, Thomas Telford Publishing, London.

Wang, L., H. Zhen H., Xinhua, C., and Xiaorun, C. (2011) "Investigation of hydration and pozzolanic reaction in silica fume-cement paste." C. Leung and K.T. Wan (eds). Advances in Construction Materials Through Science and Engineering. Proceedings of the International RILEM conference, Hong Kong, September 2011 RILEM.

Washburn, E. (1921). "Note on method of determining the distribution of pore sizes in porous materials." Proc Nat Acad Sci U.S.A. , 7(4), 115-116.

Yajun, J., and Cahyadi, J. H. (2003). "Effects of densified silica fume on microstructure and compressive strength of blended cement pastes." Cement Concrete Res, 33(10), 1543-1548. Zanni, H., Cheyrezy, M., Maret, V., Philippot, S., and Nieto, P. (1996). "Investigation of hydration and pozzolanic reaction in Reactive Powder Concrete (RPC) using 29Si NMR." Cement Concrete Res, 26(1), 93-100. 
Table 1. Chemical composition of silica fume and CEM-I 52.5, as determined by Xray fluorescence analysis.

\begin{tabular}{ccc}
\hline Compound $(\mathrm{wt} \%)$ & Microsilica 940D & CEM I 52.5 \\
\hline $\mathrm{SiO}_{2}$ & 95.8 & 19.81 \\
$\mathrm{Al}_{2} \mathrm{O}_{3}$ & 0.31 & 4.90 \\
$\mathrm{Fe}_{2} \mathrm{O}_{3}$ & 0.14 & 3.10 \\
$\mathrm{CaO}$ & 0.38 & 62.50 \\
$\mathrm{MgO}$ & 0.10 & 1.60 \\
$\mathrm{SO}_{3}$ & 0.02 & 3.66 \\
$\mathrm{~K}_{2} \mathrm{O}$ & 0.24 & 0.88 \\
$\mathrm{Na}_{2} \mathrm{O}$ & 0.08 & 0.35 \\
$\mathrm{LOI}\left(950{ }^{\circ} \mathrm{C}\right)$ & 3.85 & 2.40 \\
\hline Density $\left(\mathrm{kg} / \mathrm{m}^{3}\right)$ & 2230 & 3140 \\
Mean particle size $(\mu \mathrm{m})$ & 82.5 & 15.01 \\
\hline
\end{tabular}


Table 2. Description of mortars produced

\begin{tabular}{ccccc}
\hline Sample ID & $\begin{array}{c}\text { Type of } \\
\text { silica } \\
\text { fume* }\end{array}$ & $\begin{array}{c}\text { Silica fume content } \\
\text { as cement } \\
\text { replacement, wt.\% }\end{array}$ & $\begin{array}{c}\text { Superplasticizer } \\
\text { content (wt. } \% \\
\text { relative to binder) }\end{array}$ & $\begin{array}{c}\text { Slump } \\
(\mathrm{mm})\end{array}$ \\
\hline OPC-M & -- & -- & 0.8 & 185 \\
5DSF-M & DSF & 5 & 1.1 & 195 \\
10DSF-M & DSF & 10 & 1.2 & 185 \\
20DSF-M & DSF & 20 & 2.0 & 210 \\
5SSF-M & SSF & 5 & 1.1 & 220 \\
10SSF-M & SSF & 10 & 1.2 & 193 \\
20SSF-M & SSF & 20 & 1.1 & 200 \\
\hline
\end{tabular}

*DSF: Densified silica fume; SSF: Sonicated silica fume 
Table 3. Thermogravimetric analysis results of cement pastes

\begin{tabular}{ccccc}
\hline $\begin{array}{c}\text { Curing time } \\
(\text { days })\end{array}$ & Sample & $\begin{array}{c}\text { Total weight } \\
\text { loss }(\%)\end{array}$ & CH content $(\%)$ & $\begin{array}{c}\% \mathrm{CH} \\
\text { consumed }\end{array}$ \\
\hline \multirow{2}{*}{28} & OPC & 22.2 & 16.7 & -- \\
& DSF & 20.5 & 10.8 & 28.1 \\
& SSF & 21.4 & 4.8 & 68.1 \\
\hline \multirow{2}{*}{60} & OPC & 23.8 & 17.0 & -- \\
& DSF & 21.3 & 10.0 & 35.1 \\
& SSF & 21.0 & 3.4 & 77.6 \\
\hline
\end{tabular}


Table 4. Average chain lengths of aluminosilicate $(\overline{C L}), \mathrm{SiO}_{4}$ tetrahedra $\left(\overline{C L_{S i}}\right)$, and $\mathrm{Al}_{\text {IV }} / \mathrm{Si}$ ratio for the C-S-H phase in hydrated pastes with DSF and SSF.

\begin{tabular}{cccccc}
\hline & $\mathrm{Q}^{\mathrm{n}}$ species & $\begin{array}{c}\text { Peak centre of } \\
\text { gravity }\end{array}$ & $\begin{array}{c}\text { Relative peak } \\
\text { intensity }\end{array}$ & $\overline{C L}$ & $\mathrm{Al} / \mathrm{Si}$ \\
\hline \multirow{4}{*}{$\mathrm{DSF} \quad \mathrm{Q}^{0}$} & -72.8 & 10.72 & & \\
& $\mathrm{Q}^{1}$ & -80.5 & 21.73 & & \\
& $\mathrm{Q}^{2}(1 \mathrm{Al})$ & -83.4 & 3.73 & & \\
& $\mathrm{Q}^{3}$ & -86.1 & 20.05 & & 0.041 \\
& $\mathrm{Q}^{4}$ & -110.5 & 14.33 & & \\
\hline $\mathrm{SSF} \quad \mathrm{Q}^{2}(1 \mathrm{Al})$ & -72.8 & 29.44 & & \\
& $\mathrm{Q}^{0}$ & -80.4 & 8.27 & & \\
& $\mathrm{Q}^{2}(0 \mathrm{Al})$ & -86.3 & 21.14 & & \\
& $\mathrm{Q}^{4}$ & -109.5 & 13.60 & 6.6 & 0.084 \\
& & & 35.39 & & \\
\hline
\end{tabular}


A. SSF

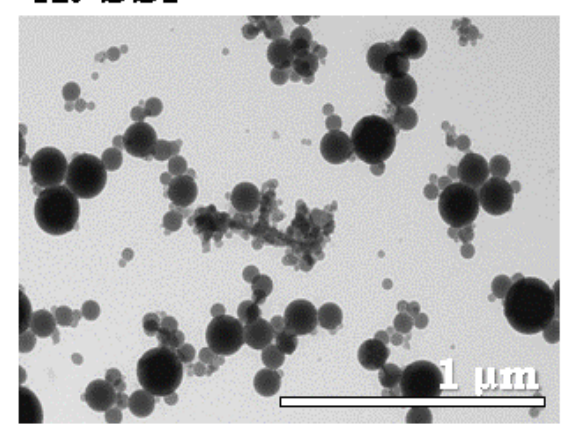

B. DSF

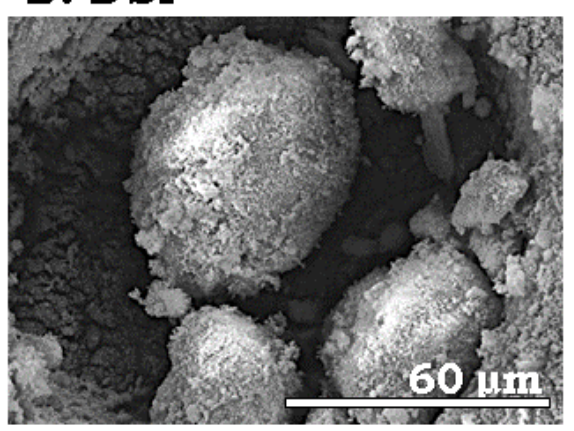

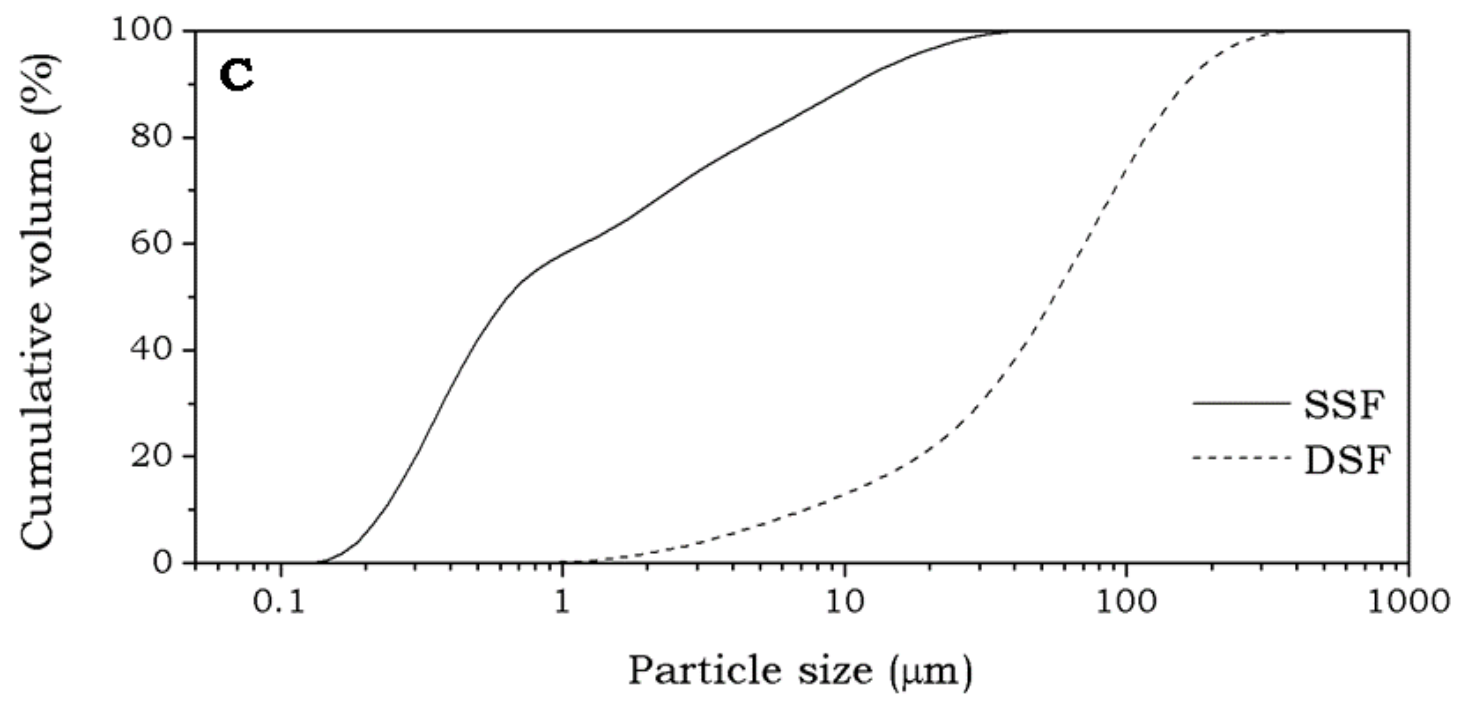

Figure 1. Effect of the sonication treatment applied to densified silica fume (DSF) in the particle size distribution. (A) Image of SSF obtained by transmission electron microscopy (TEM). (B) Image of DSF obtained by scanning electron microscopy (SEM). (C) Particle size distributions of DSF and SSF. 


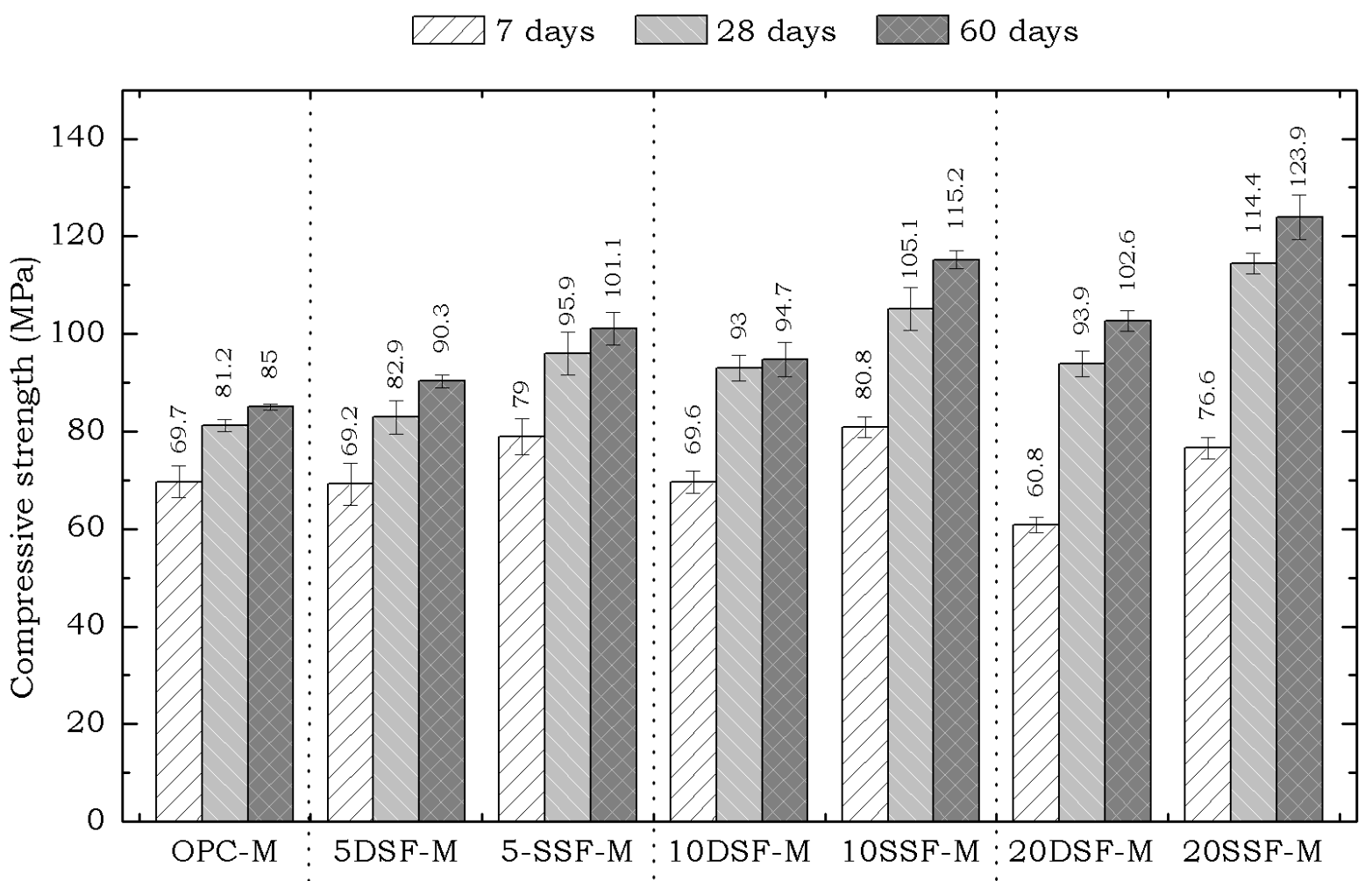

Figure 2. Compressive strengths of mortars produced with OPC/DSF and OPC/SSF blends, as a function of the amount of pozzolan incorporated in the binder 
A.

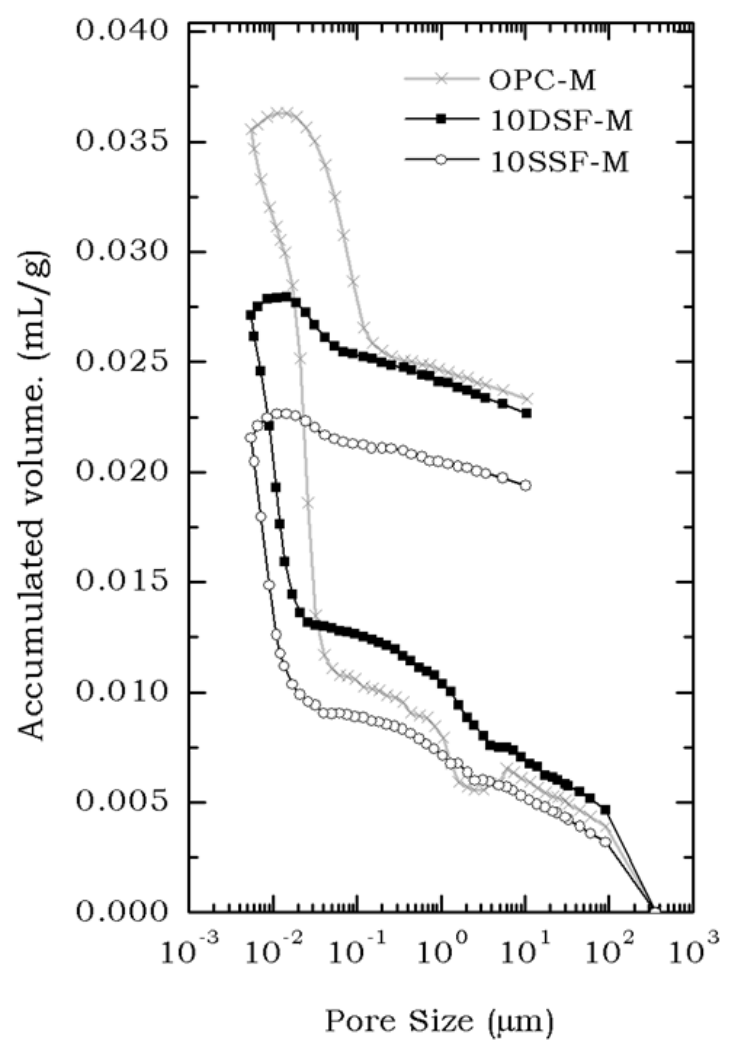

B.

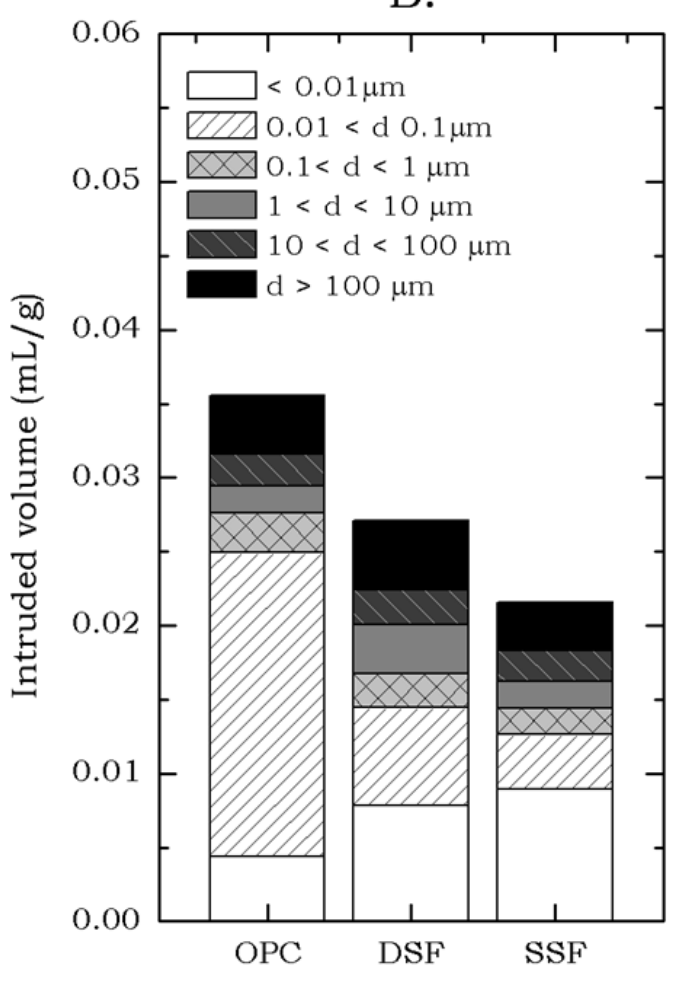

Figure 3. Mercury intrusion porosimetry (MIP) data for a reference mortar without mineral admixture (OPC), and mortars with $10 \%$ cement replacement by DSF and

SSF, after 28 days of curing: A Cumulative volume of mercury intruded as a function of pore diameter as calculated from intrusion pressure via the Washburn equation; B) Pore size distributions obtained from MIP data 


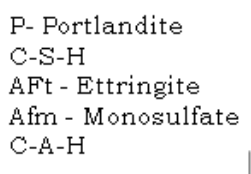

A. 28 days
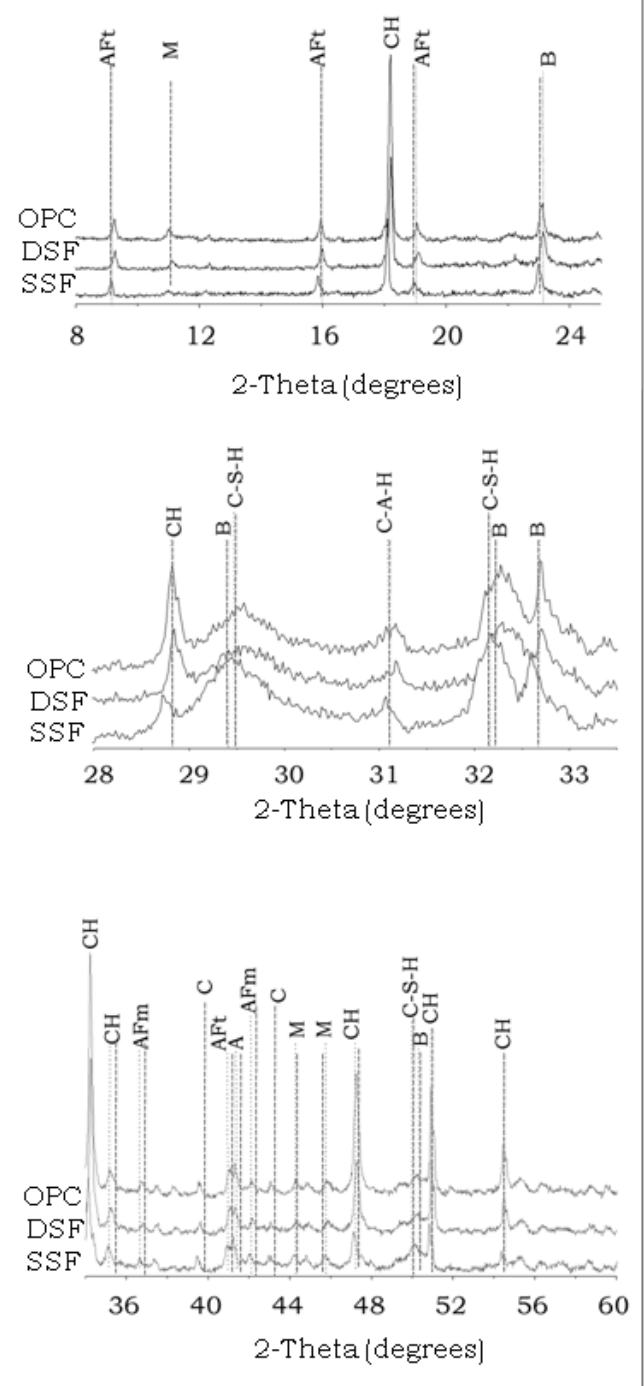

M-Monocarbonate

C- Calcite

B - Belite

A - Alita

B. 60 days
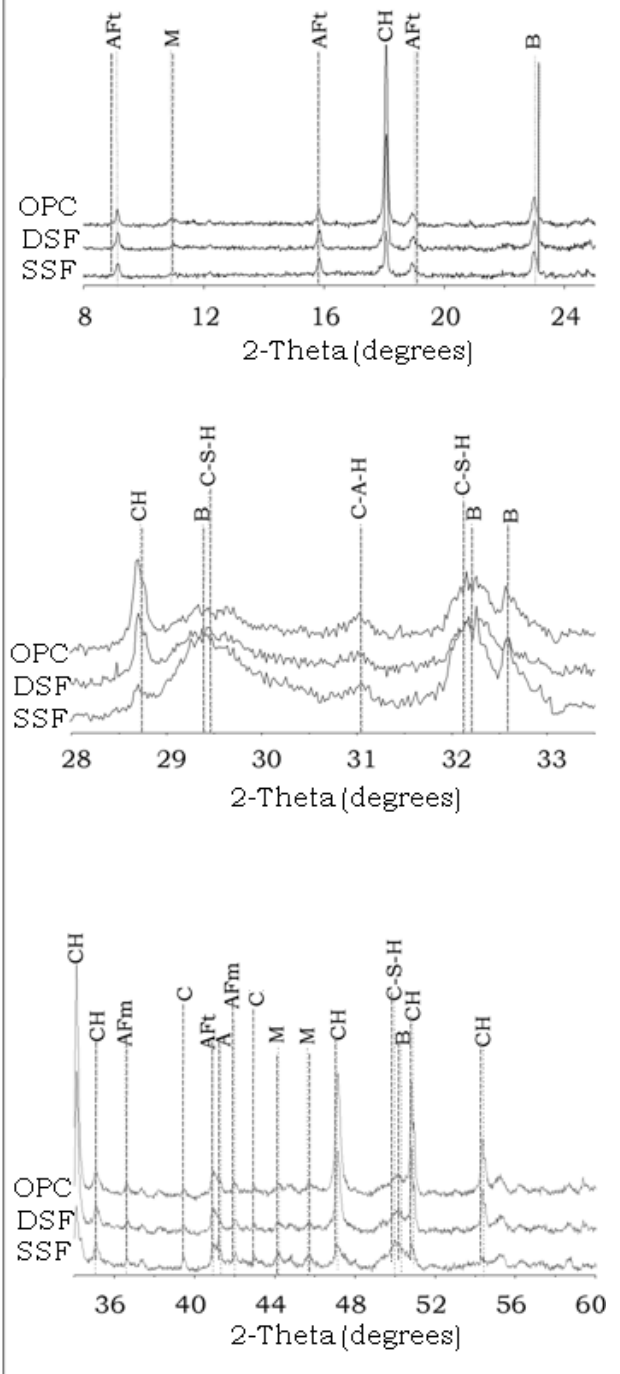

Figure 4. X-ray diffraction of the reference paste (OPC) and pastes with densified silica fume (DSF) and sonicated silica fume (SSF) with (a) 28 and (b) 60 days of curing 
A. 28 days

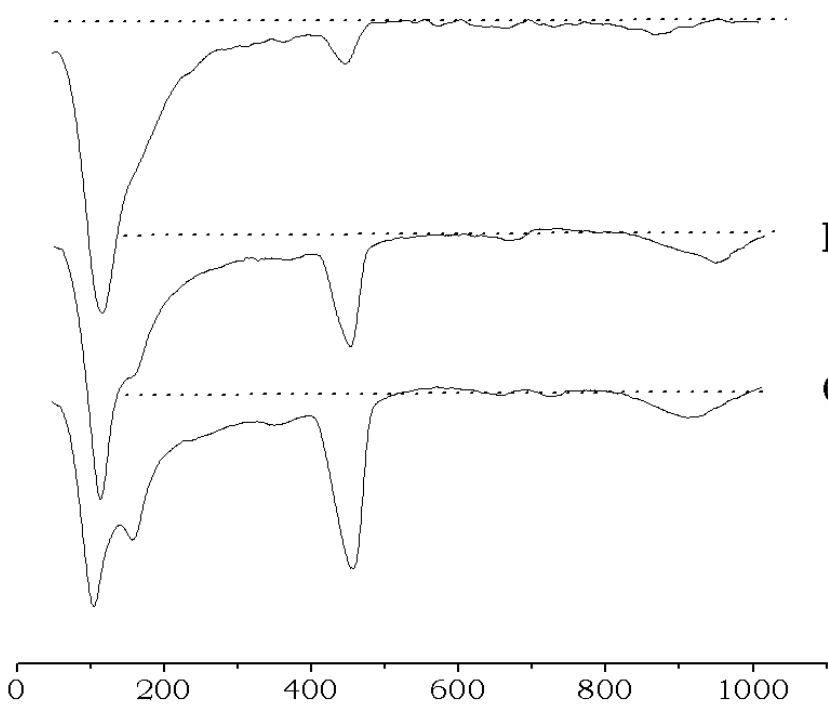

Temperature $\left({ }^{\circ} \mathrm{C}\right)$
B. 60 days

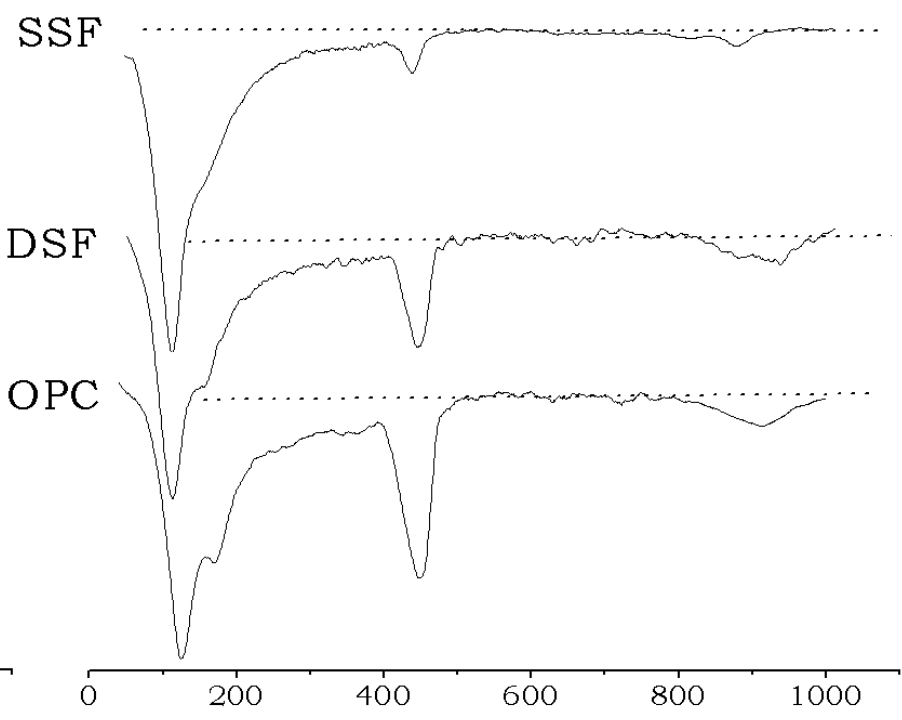

Temperature $\left({ }^{\circ} \mathrm{C}\right)$

Figure 5. Differential thermogravimetric curves (DTG) of pastes with densified silica fume (DSF), sonicated silica fume (SSF) and the reference paste without any silica admixture (OPC) 

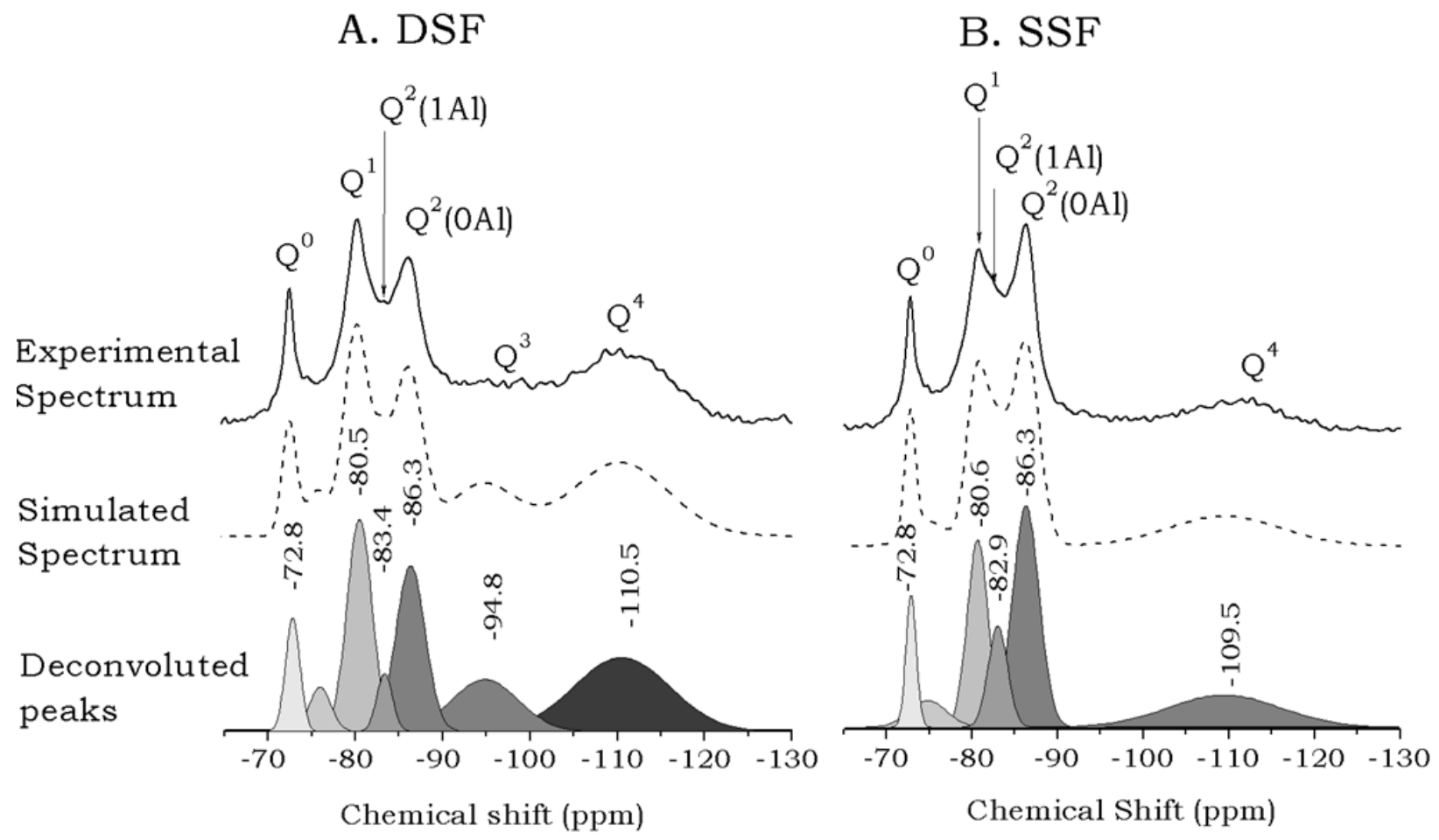

Figure 6. Solid-state ${ }^{29} \mathrm{Si}$ MAS NMR spectra $\left(14.1 \mathrm{~T}, v_{\mathrm{R}}=10.0 \mathrm{kHz}\right)$ of blended pastes with $10 \%$ (a) densified silica fume (DSF) or (b) sonicated silica fume (SSF), recorded after 28 days of curing 


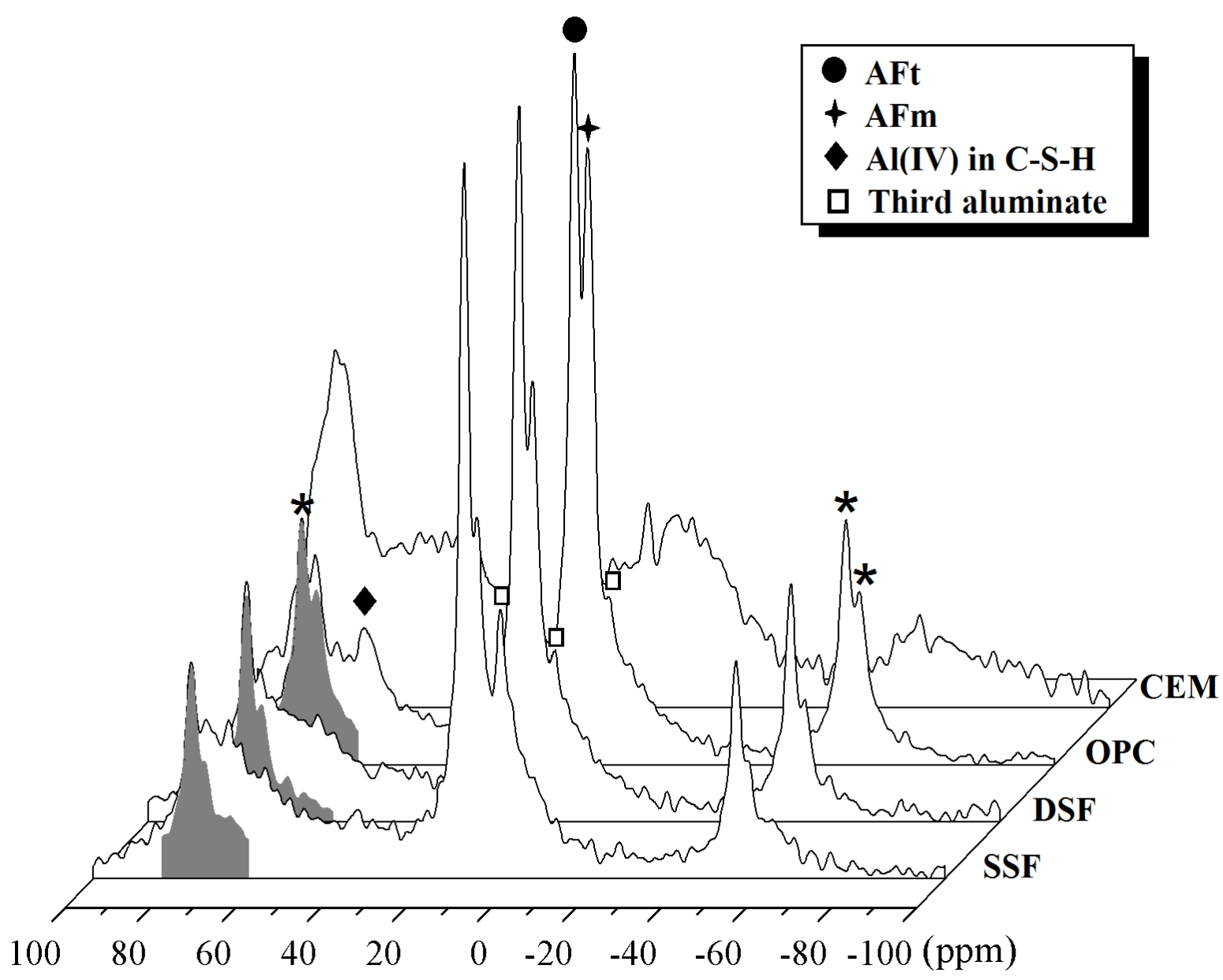

Figure 7. Solid-state ${ }^{27} \mathrm{Al}$ MAS NMR spectra $\left(14.1 \mathrm{~T}, v_{\mathrm{R}}=10.0 \mathrm{kHz}\right)$ of anhydrous cement (CEM), hydrated Portland cement (OPC) and blended pastes with $20 \%$ densified silica fume (DSF) or sonicated silica fume (SSF), recorded after 28 days of curing. Spinning sidebands are marked with *; to visually enable separation of the $75 \mathrm{ppm}$ spinning sideband and the peak due to $\mathrm{Al}(\mathrm{IV})$ in $\mathrm{C}-\mathrm{S}-\mathrm{H}$, the shaded regions indicate the shape of the -50ppm sideband replicated on the opposite side of the centerband as an approximation of the sideband position and intensity within this region. 


\section{A. SSF}
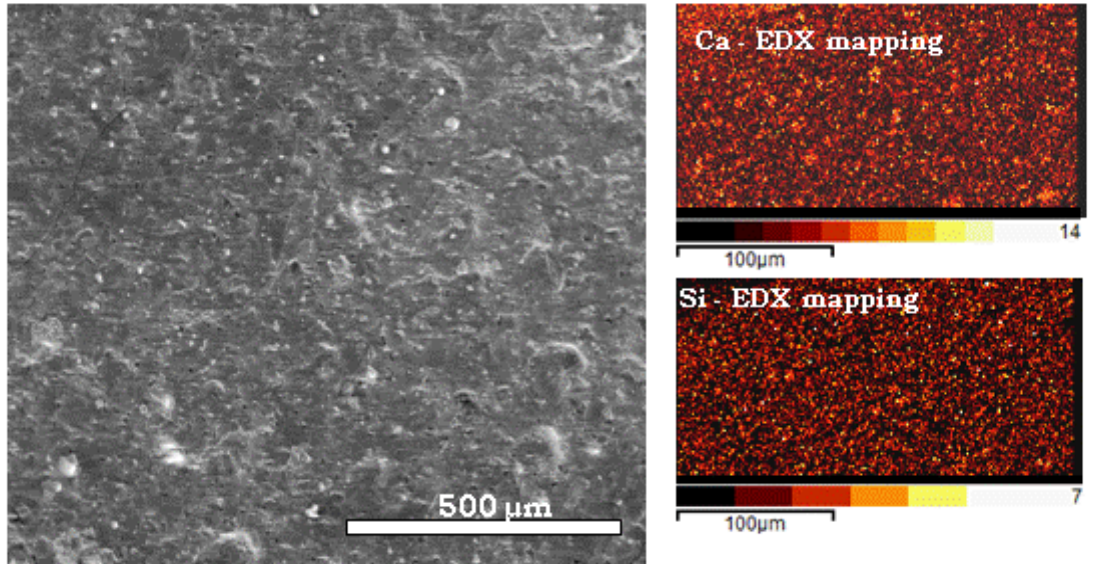

\section{B. DSF}
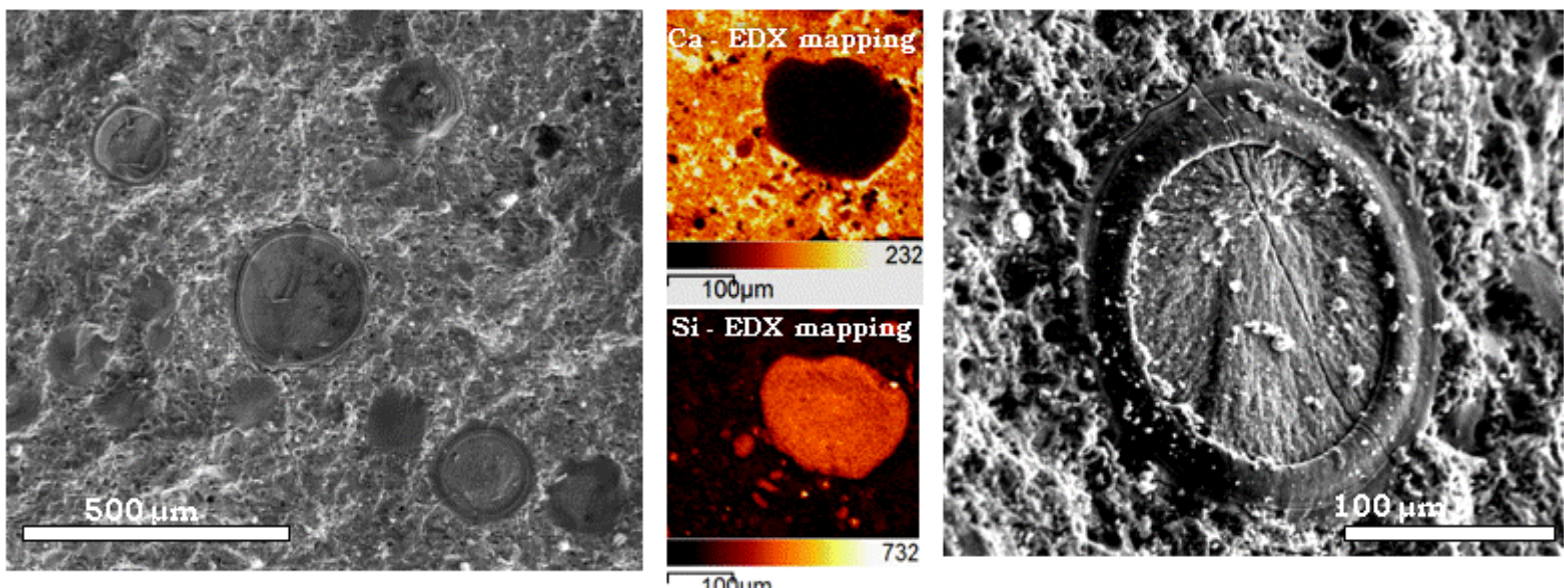

$100 \mu \mathrm{m}$

Figure 8. Scanning electron microscopy images of pastes after 28 days of curing. (A) SSF-blended cement; (B) DSF-blended cement; and EDX mapping analysis of Ca and $\mathrm{Si}$. 